
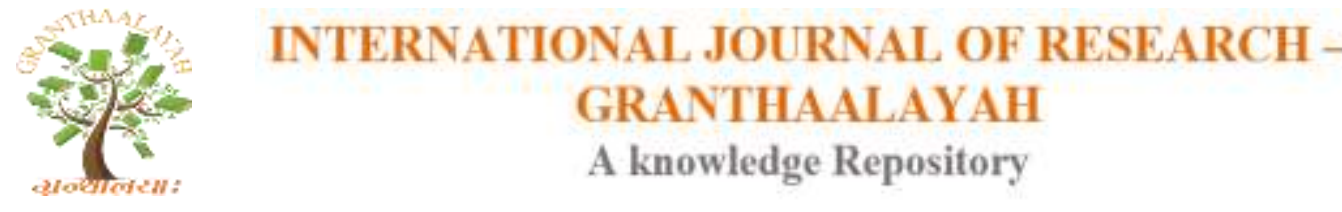

Social

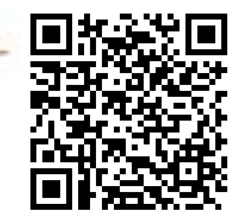

\title{
STUDY ON SELF-CONFIDENCE CONTRIBUTING TO SUPERSTITIOUS BEHAVIOR
}

\author{
Dr. Manasvi Shrivastav ${ }^{* 1}$ \\ ${ }^{* 1}$ Department of Clinical Psychology, Dev Sanskriti Vishwavidyalaya, Haridwar (UK), India
}

\begin{abstract}
The purpose of the study was to assess the effect of self-confidence on superstitious behavior of people of UP. 300 participants were selected through quota sampling from various places of UP. Age and education related factors treated as controlled variables. ASCI (Agnihotry's SelfConfidence Inventory) of Rekha Agnihotry(1987) has been used, consisting 40 items. Superstitious behavior scale (self-constructed) has been used, which also consisting 40 items. Each item have three alternatives: (a) I will definitely do it. (b) If not possible, I will not do it. (c) I don't believe in it. Ex-post facto research design is used. Data was analysed by Chi-square technique. Result show that low self-confidence is responsible for high of superstitious behavior.
\end{abstract}

Keywords: Self-Confidence; Superstitious Behavior; Rural Female; Rural Male; Urban Female; Urban Male.

Cite This Article: Dr. Manasvi Shrivastav. (2017). "STUDY ON SELF-CONFIDENCE CONTRIBUTING TO SUPERSTITIOUS BEHAVIOR.” International Journal of Research Granthaalayah, 5(7), 219-228. https://doi.org/10.29121/granthaalayah.v5.i7.2017.2128.

\section{Introduction}

In the literature, there are several definitions on superstition. Most authors agree on the fact that superstitions are beliefs or behaviors that are contrary to rational norms within a specific society. It implies that superstitious behaviors cannot be interpreted or explained according to religious beliefs which are usually not considered as irrational by members of a given society (Campbell, 1996). Superstitions are culturally anchored and differ according to countries. For example Simmons and Schindler (2002) demonstrate that, in China, prices ending with the digit 8 are very common because there is a local belief that number 8 brings luck, prosperity, and happiness. On the contrary, prices ending with digit 4 are under - represented because this number brings bad luck.

Superstition is defined as "beliefs and/or practices that have no religious no scientific foundations and which lead people to think that certain facts (external events or one's own actions) or objects can bring good or bad luck, or be signs announcing positive or negative consequences" by Eva Delacroix and Valerie Guillard. 
According to Devenport and Holloway, (1980), superstitious rituals are usually taking place in contexts of uncertainty. In a later article (Skinner, 1953), he suggested that seeing a causal relationship between behavior and the "consequences" also could explain the occurrence and maintenance of superstition in humans. A second, complementary explanation may be derived from Langer and colleagues' (Langer, 1975, 1977; Langer \& Roth, 1975) work on illusion of control. Langer stated that, in general, people are inclined to see themselves as a cause, even in situations in which they are not influencing the situation. This explanation holds that people carry out superstitious behaviours in order to influence situations in which, in reality, they have no control. According to Langer, this is especially true in situations in which chances as well as skill play a role. In competitive sports, there is always a mixture of chance as well as skill that determines the outcome of a match. Therefore, in these situations, people will probably be more prone to the illusion of control and superstition.

To establishing control over uncertain situations, the uses of superstitious behaviours are thought to lead to greater levels of self-efficacy (Wright \& Erdal, 2008). Self-efficacy refers to an individual's level of confidence in their ability to successfully perform and/or accomplish a task (Feltz, Short, \& Sullivan, 2008). It was found that the inclusion of a superstition increased the perceived self-efficacy of participants, leading to improved performance. (Damisch et al, 2010) Conversely, individuals who feel they have no control whatsoever over a situation, and who fail to avail themselves of superstitious behavioural techniques to try and gain a certain amount of control, often display low self-efficacy and learned helplessness-type behaviours (Bandura, 1997; Hanley \& Long, 1995, as cited in Brebner, 2012). Learned helplessness is said to occur when an organism learns that their actions have no impact on a repeatedly being demoralized by uncontrollable life events. Once learned helplessness is acquired, even if the situation changes, allowing the organism to successfully escape the aversive event, the organisms lack of responding will persist (Martinko \& Gardner, 1982 as cited in Brebner, 2012).

There is evidence suggesting that uncertainty regarding future outcome is an important determinant of superstition. For example, it often has been assumed that the illusion of control tend to be more pronounced for situations in which not only skill but also chance play a substantial role (Langer, 1975, 1977; Langer \& Roth, 1975). It has been argued that people may react to uncertain and unpredictable situations with superstitious beliefs or actions. (Malinovski, 1955; Vyse, 1997)

Research has been conducted by John Sachs to study the relation between superstition and selfefficacy titled "Superstition and self-efficacy in Chinese post graduate students" found that higher scores on belief in superstition were associated with lower rated self-efficacy.

It has been examined that desire to maintain a sense of control over one's environment has been one of key motivations behind superstitious behaviour. (Ryan M. Moyer, 2010). Ryan M. Moyer investigated relation of superstitious behaviour within the context of the self-concept and selfintegrity in his dissertation "Maintaining self-integrity through superstitious behaviour", studies $1 \mathrm{a}$ and $1 \mathrm{~b}$ did not find any evidence that manipulating the self-concept prior to an event designed to evoke superstition would increase the desire to engage in superstitious behaviour. Study 2 provided evidence that superstitious behaviour is motivated by a desire to maintain self-integrity. Consequently, while superstitious behaviour may be triggered by control threats, it may also 
occur as a result of any general threat to self-integrity. Moreover, if superstitious behaviour is motivated by the desire to maintain overall self-integrity, then depriving individuals of a chance to engage in superstitious behaviour should elicit subsequent attempts to repair self-integrity via alternative means.

Although science makes progress, but still people stick to believe in superstitions and follow the superstitious rituals. What are the reasons behind it? Is it rational or some sort of psychological factors lying behind it? In present study researcher study the relation between self-confidence and superstitious behaviour.

In 1943, Abraham Maslow in his paper "A Theory of Human Motivation" argued that an individual only was motivated to acquire self-confidence (one component of "esteem") after he or she had achieved what they needed for physiological survival, safety, love and belonging. He claimed that satisfaction of self-esteem led to feelings of self-confidence that, once attained, led to a desire for "self-actualization."

Self Confidence is one of the personality trait which is a composite of a person's thoughts and feelings, strivings and hopes, fears and fantasies, his view of what he is, what he has been, what he might become, and his attitudes pertaining to his worth.(Dr. Manisha Goel, Dr. Preeti Aggarwal, 2012).

Research problem: - "Is self-confidence is responsible for superstitious behaviour?"

\section{Objectives}

1) To study the relation between self-confidence and superstitious behaviour among Rural Female.

2) To study the relation between self-confidence and superstitious behaviour among Rural Male.

3) To study the relation between self-confidence and superstitious behaviour among Urban Female.

4) To study the relation between self-confidence and superstitious behaviour among Urban Male.

Moyer, R.M.(2010) examined three studies to establish this link between self-functioning and superstitious behavior. Studies $1 \mathrm{a}$ and $1 \mathrm{~b}$ did not find any evidence that manipulating the selfconcept prior to an event designed to evoke superstition would increase the desire to engage in superstitious behavior. Threatening or boosting one's self-esteem prior to a game of chance did not affect participant's desire to use superstitious strategy (aura color). Study 2 provided evidence that superstitious behavior is motivated by a desire to maintain self-integrity by showing that individuals deprived of their aura color prior to a game of chance were more likely to engage in self-affirmation subsequently. It also showed that the impact of depriving individuals of a superstitious strategy is independent of belief in such strategy.

Damisch, L., Stoberock, B., Musweiler, T.(2010) found that activating good-luck-related superstitions via a common saying or action (e.g. "break a leg", keeping one's fingures crossed) or a lucky charm improves subsequent performance in golfing, motor dexterity, memory, and 
anagram games. These performance benefits are produced by changes in perceived self-efficacy. Activating a superstition boosts participant's confidence in mastering upcoming tasks, which in turn improves performance. Experiments shows that increased task persistence constitutes one means by self-efficacy, enhanced by superstition, improves performance.

\section{Variables}

\section{Independent Variable}

Self-confidence is the independent variable in this research. Self Confidence is one of the personality trait which is a composite of a person's thoughts and feelings, strivings and hopes, fears and fantasies, his view of what he is, what he has been, what he might become, and his attitudes pertaining to his worth (Dr. Manisha Goel, Dr. Preeti Aggarwal, 2012). In 1943, Abraham Maslow in his paper "A Theory of Human Motivation" argued that an individual only was motivated to acquire self-confidence (one component of "esteem") after he or she had achieved what they needed for physiological survival, safety, and love and belonging. He claimed that satisfaction of self-esteem led to feelings of self-confidence that, once attained, led to a desire for "self-actualization."

\section{Dependent Variable}

Superstitious behaviour is the dependent variable in this research. A stricter definition of the superstition (which, following Hood 2010, we henceforth refer to as a 'supernatural superstition') is one where there are no rational grounds to believe in a relationship between action and outcome, so that the agents prior belief is that the relationship is unlikely.

\section{Hypothesis}

1) There is no significant relationship between self-confidence and superstitious behaviour among rural female.

2) There is no significant relationship between self-confidence and superstitious behaviour among rural male.

3) There is no significant relationship between self-confidence and superstitious behaviour among urban female.

4) There is no significant relationship between self-confidence and superstitious behaviour among urban male.

\section{Materials and Methods}

\section{Sample and Sampling}

- Sample is divided into four categories: - Rural Female, Urban Female, Rural Male and Urban Male.

- Total 300 people has been chosen for the sample from UP.

- "Quota sampling" has been used in this research.

- Uttar Pradesh is the area chosen for sampling. Age limit of sample is 20 years to 40 years.

- "Ex-post facto" research design has been used for this research. 


\section{Tools}

- To assess the Self-confidence,"Agnihotry's Self-confidence Inventory (ASCI)" of Agnihotry Rekha(1987), P.G. Department of psychology, R.G.College, Meerut is used. Reliability through split-half method is 0.91 , K-R Formula $20-0.89$ and Test-retest method is 0.78 . In item-analysis validity coefficients were determined for each item by biserial correlation method and only those items were retained which yielded 0.25 or above biserial correlation with the total score. The inventory was also validated by correlating the scores obtained by the subject on Basavanna's (1975) self-confidence inventory. The validity coefficient obtained is 0.82 which is significant beyond 0.01 level. The inventory can be scored by hand.

- To assess superstitious behaviour, scale has been developed by researcher. Reliability coefficient of scale has been found by test-retest method, which was found 0.90 . The Scale has shown content validity on the basis of experts rating, which were considered satisfactory.

\section{Statistical Method Used}

Chi Square has been used as statistical method to calculate the result.

\section{Result}

$\mathrm{H}_{1}=$ There is no significant relationship between self-confidence and superstitious behaviour among rural female.

\section{Rural Female}

Table 1: Percentage table

\begin{tabular}{|l|l|l|l|}
\hline Superstitious behaviour & Above Average & Average & Below Average \\
\hline Self-confidence & & & \\
\hline Above Average & 16 & 42 & 42 \\
\hline Average & 0 & 56 & 44 \\
\hline Below Average & 44 & 44 & 42 \\
\hline
\end{tabular}

Table 2: Contingency Table

\begin{tabular}{|l|l|l|l|l|}
\hline \multirow{2}{*}{ Superstitious Behaviour } & \multirow{2}{*}{ Above Average } & Average & Below Average & Total \\
\cline { 1 - 4 } Above Average & 02 & 05 & 05 & \\
\hline Average & $(2.88)$ & $(5.76)$ & $(3.36)$ & 12 \\
& 0 & 15 & 12 & \\
\hline Below Average & $(6.48)$ & $(12.96)$ & $(7.56)$ & 27 \\
\hline Total & 16 & 16 & 04 & 36 \\
\hline & $(8.64)$ & $(17.28)$ & $(10.08)$ & 75 \\
\hline
\end{tabular}

After calculation the value $\mathrm{X} 2=20.59$, on $\mathrm{df}=4$. P lies below 0.01 . It has been clear from above table that relation between self-confidence and Superstitious Behavior is significant. Hence, 
hypothesis is not accepted. Result indicates that low level of self-confidence promotes high superstitious behaviour among Rural Female.

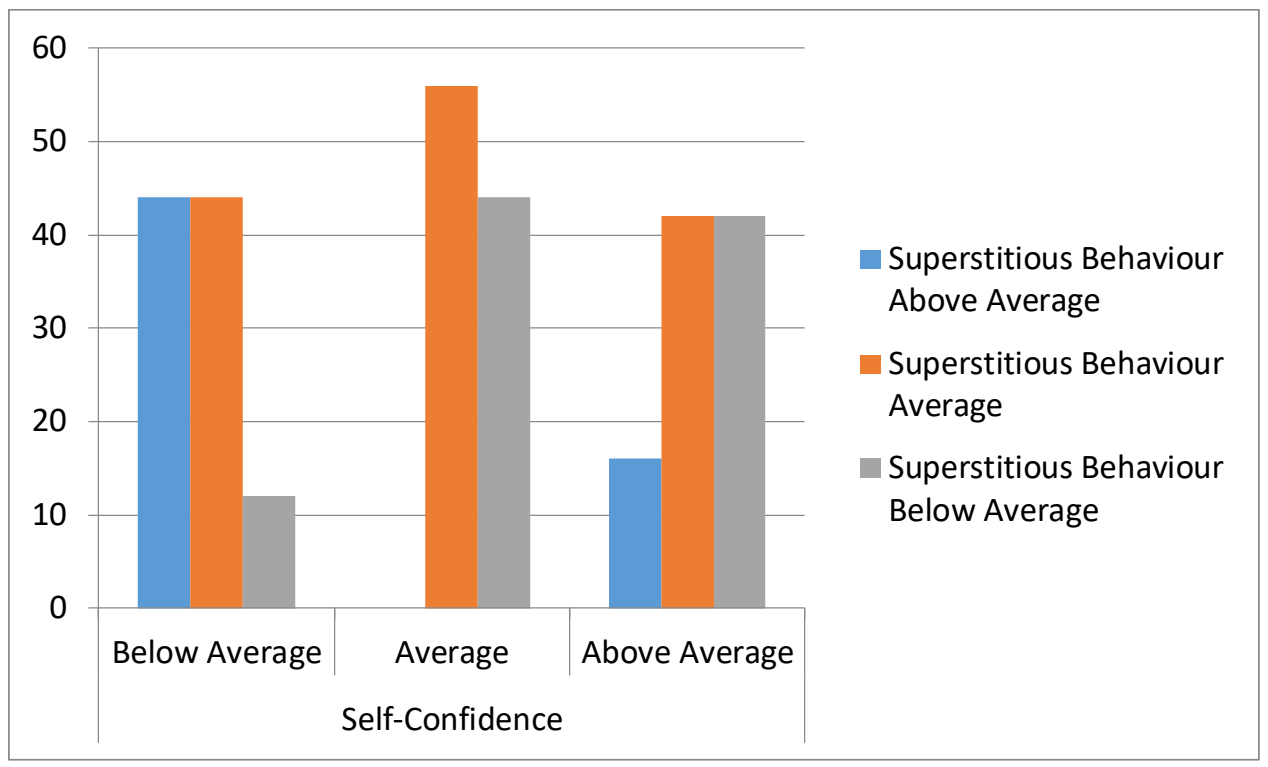

Graph 1: Percentage shows relationship between superstitious behaviour and self-confidence among rural female.

\section{Rural Male}

$\mathrm{H}_{2}=$ There is no significant relationship between self-confidence and superstitious behaviour among rural male.

Table 3: Percentage Table

\begin{tabular}{|l|l|l|l|}
\hline Superstitious behaviour & \multirow{2}{*}{ Above Average } & Average & \multirow{2}{*}{ Below Average } \\
\cline { 1 - 3 } Self-confidence & & & 31 \\
\hline Above Average & 5 & 64 & 18 \\
\hline Average & 7 & 75 & 8 \\
\hline Below Average & 80 & 12 & 3 \\
\hline
\end{tabular}

Table 4: Contingency Table

\begin{tabular}{|l|l|l|l|l|}
\hline Superstitious Behaviour & \multirow{2}{*}{ Above Average } & Average & Below Average & Total \\
\cline { 1 - 4 } Self-confidence & & & & \\
\cline { 1 - 5 } Above Average & 01 & $\begin{array}{l}14 \\
(11.15)\end{array}$ & $\begin{array}{l}07 \\
(4.11)\end{array}$ & 22 \\
\hline Average & $02.75)$ & 21 & 05 & \\
& $(8.59)$ & $(14.19)$ & $(5.23)$ & 28 \\
\hline Below Average & 20 & 03 & 02 & \\
& $(7.67)$ & $(12.67)$ & $(4.67)$ & 25 \\
\hline Total & 23 & 38 & 14 & 75 \\
\hline
\end{tabular}


After calculation the value $\mathrm{X}^{2}=44.71$, on $\mathrm{df}=4$. P lies below 0.01 . It has been clear from above table that relation between self-confidence and Superstitious Behavior is significant. Hence, hypothesis is not accepted. Result indicates that low level of self-confidence promotes high superstitious behaviour among rural male.

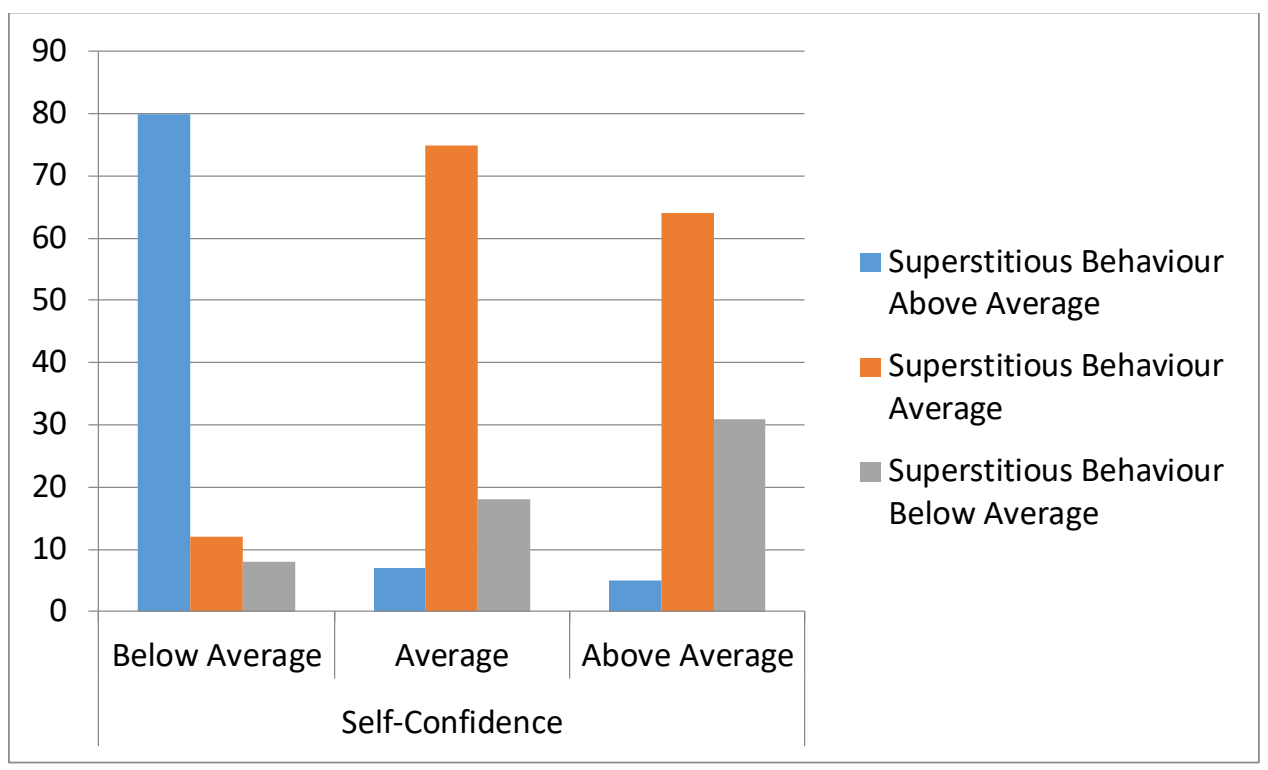

Graph 2: Percentage shows relationship between superstitious behaviour and self-confidence among rural male.

$\mathrm{H}_{3}=$ There is no significant relationship between self-confidence and superstitious behaviour among urban female.

\section{Urban Female}

Table 5: Percentage Table

\begin{tabular}{|c|c|c|c|}
\hline Superstitious behaviour & \multirow[b]{2}{*}{ Above Average } & \multirow[b]{2}{*}{ Average } & \multirow[b]{2}{*}{ Below Average } \\
\hline Self-confidence & & & \\
\hline Above Average & 6 & 31 & 63 \\
\hline Average & 8 & 56 & 36 \\
\hline Below Average & 59 & 24 & 17 \\
\hline
\end{tabular}

Table 6: Contingency Table

\begin{tabular}{|l|l|l|l|l|}
\hline Superstitious Behaviour & Above Average & Average & Below Average & Total \\
\cline { 1 - 4 } Self-confidence & & & & \\
\cline { 1 - 5 } Above Average & 01 & 5 & 10 & 16 \\
& $(4.9)$ & $(5.76)$ & $(5.33)$ & \\
\hline Average & 2 & 14 & 9 & 25 \\
& $(7.66)$ & $(9)$ & $(8.33)$ & 34 \\
\hline Below Average & 20 & 8 & 6 & 75 \\
\hline Total & $(10.43)$ & $(12.24)$ & $(11.33)$ & 25 \\
\hline
\end{tabular}


After calculation the value $\mathrm{X}^{2}=27.662$, on $\mathrm{df}=4$. $\mathrm{P}$ lies below 0.01 . It has been clear from above table that relation between self-confidence and superstitious Behavior is significant. Hence, hypothesis is not accepted. Result indicates that low level of self-confidence promotes high superstitious behaviour among Urban Female.

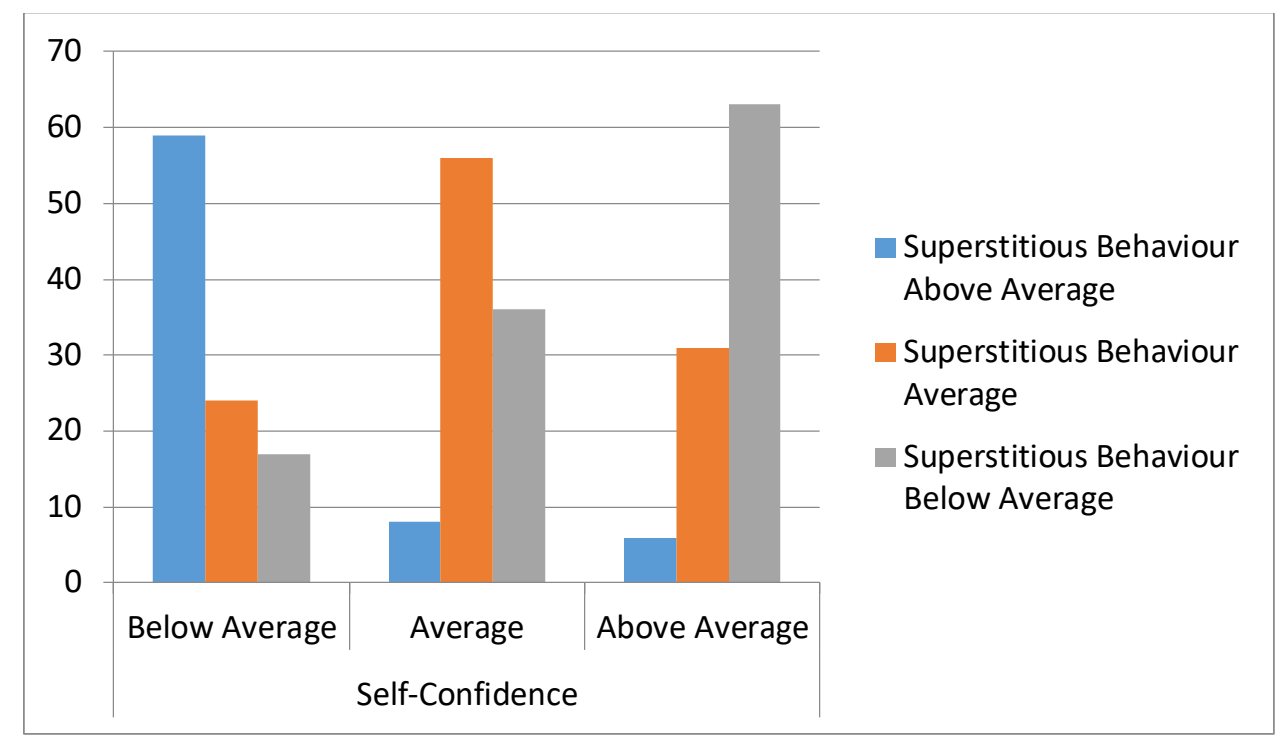

Graph 3: Percentage shows relationship between superstitious behaviour and self-confidence among urban female.

$\mathrm{H}_{4}=$ There is no significant relationship between self-confidence and superstitious behaviour among urban male.

\section{Urban Male}

Table 7: Percentage Table

\begin{tabular}{|l|l|l|l|}
\hline Superstitious Behaviour & \multirow{2}{*}{ Above Average } & Average & \multirow{2}{*}{ Below Average } \\
\cline { 1 - 4 } Self-confidence & & 38 & 46 \\
\hline Above Average & 16 & 61 & 11 \\
\hline Average & 28 & 33 & 0 \\
\hline
\end{tabular}

Table 8: Contingency Table

\begin{tabular}{|c|c|c|c|c|}
\hline Superstitious Behaviour & \multirow[t]{2}{*}{ Above Average } & \multirow[t]{2}{*}{ Average } & \multirow[t]{2}{*}{ Below Average } & \multirow[t]{2}{*}{ Total } \\
\hline Self-confidence & & & & \\
\hline Above Average & $\begin{array}{l}05 \\
(11.2) \\
\end{array}$ & $\begin{array}{l}11 \\
(12.4) \\
\end{array}$ & $\begin{array}{l}14 \\
(6.4)\end{array}$ & 30 \\
\hline Average & $\begin{array}{l}5 \\
(6.72) \\
\end{array}$ & $\begin{array}{l}11 \\
(7.44)\end{array}$ & $\begin{array}{l}2 \\
(3.84) \\
\end{array}$ & 18 \\
\hline Below Average & $\begin{array}{l}18 \\
(10.08)\end{array}$ & $\begin{array}{l}9 \\
(11.16)\end{array}$ & $\begin{array}{l}0 \\
(5.76) \\
\end{array}$ & 27 \\
\hline Total & 28 & 31 & 16 & 75 \\
\hline
\end{tabular}


After calculation the value $\mathrm{X}^{2}=28.035$, on $\mathrm{df}=4$. P lies below 0.01 . It has been clear from above table that relation between self-confidence and Superstitious Behavior is significant. Hence, hypothesis is not accepted. Result indicates that low level of self-confidence promotes high superstitious behaviour among Urban Male.

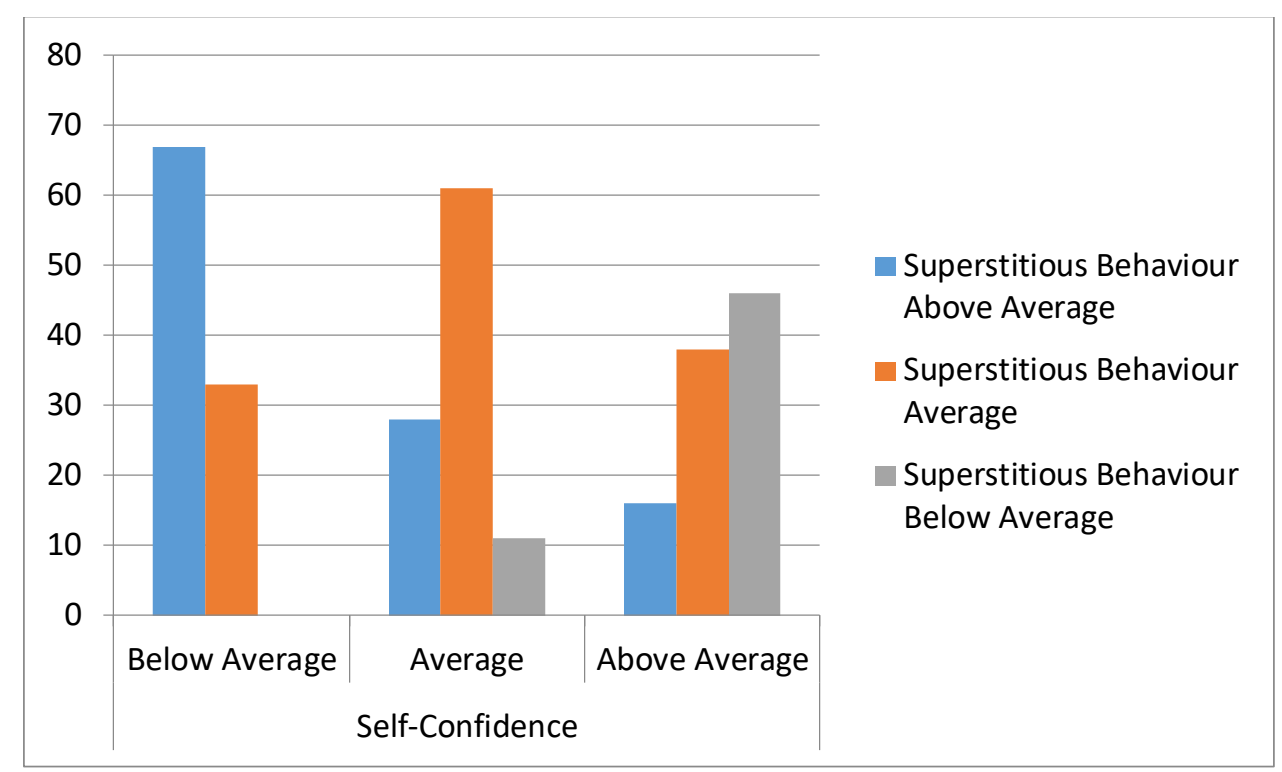

Graph 4: Percentage shows relationship between superstitious behaviour and self-confidence among urban male.

\section{Discussion}

Results supported by previous researches of R.M. Moyer (2010) provided evidence that superstitious behaviour is motivated by a desire to maintain self-integrity. Damisch et.al. (2010) found that the inclusion of a superstition increased the perceived self-efficacy of participants leading to improved performance. Individuals who feel they have no control whatsoever over a situation and who fail to avail themselves of superstitious behavioural techniques to try and gain a certain amount of control, often display low self-efficacy and learned helplessness type behaviours. (Bandura, 1997, Hanley \& Long, 1995, as cited in Wright \& Erdal, 2008).

Research has been conducted by John Sachs to study the relation between superstition and selfefficacy, found that higher scores on belief in superstition were associated with lower rated selfefficacy.

Stanke, (2004) concluded, while superstitious behaviour may be triggered by control threats, it may also occur as a result of any general threat to self-integrity. Moreover, if superstitious behavior is motivated by the desire to maintain overall self-integrity, then depriving individuals of a chance to engage in superstitious behaviour should elicit subsequent attempts to repair selfintegrity via alternative means. If individuals with strong superstitious beliefs do find a need to cope with life's uncontrollability, it is possible that these individuals also have problems with self-concept. 


\section{Conclusion}

Present research work try to fill the knowledge gap of underlying phenomena responsible for superstitious behavior among people. This research concluded that people usually believe or follow superstitious behavior when they have low self-confidence. Superstitious behavior is helpful in improving self-confidence. But superstitious behavior is a self-deceiving process; individual should use some other techniques to regain the self-confidence.

\section{References}

[1] Agnihotry, R. (1987). Agnihotry's Self-Confidence Inventory [Measurement Instrument]. Agra, UP: National Psychological Corporation

[2] Brebner,K.(19,Feb.,2012). Superstitions:Illogical phenomena? Or Uniquely useful behaviours? By Sigmund Freud. Retrieved from: http://people.stfx.ca/kbrebner/sample\%20paper\%20Intro.pdf

[3] Campbell, (1996). Half Belief and the paradox of Ritual Instrumental Activism: A Theory of Modern Superstition. The British Journal of Sociology, 47,1,151-166.

[4] Damisch, L.,Stoberock, B.,Mussweiler ,T. (2010). Keep your fingers crossed! How superstition Improves Performance. Psychological Science. 21(7). 1014-1020. Retrieved from: DOI: 10.1177/0956797610372631.

[5] Feltz, D.L.,Short S.E., Sullivan, P.J. (2008). Self-efficacy in sport. [Human Kinetics]. Part 1.Retrieved from: https://books.google.co.in/

[6] Langer, E.J. (1977). The Psychology of chance. Journal for the Theory of Social Behaviour, 7(2).185-203. Retrieved from: DOI: 10.1111/j.1468-5914.1977.tb00384.x

[7] Langer, E.J., Roth, J. (1975). Heads I win, tails it's chance: The illusion of control as a function of sequence of outcomes in a purely chance task. Journal of Personality and social psychology, 32, 951-955. Retrieved from: http://dx.doi.org/10.1037/0022-3514.32.6.951

[8] Malinowski (1948). Myth in Primitive Psychology. Magic, Science and religion and other essays. New Delhi: Kessinger Publishing.

[9] Moyer, R.M.(2010). Maintaining self-integrity through superstitious behavior. [HKU SPACE]. Retrieved from: http://sunzi.lib.hku.hk/ER/detail/hkul/4573116

[10] Piaget,J.(1928).The child's conception of the world. London. Routledge and Kegan Paul.

[11] Sachs, J. (2004). Superstition and self-efficacy in Chinese Post Graduate students. Psychological Reports.95(2). pp. 485-486.Retrieved from: DOI: 10.2466/PR0.95.6.485-486

[12] Shrivastav, M. (2017). Superstitious behavioral scale. A study of psycho-social factors contributing to superstitious behavior. Unpublished thesis.

[13] Simmons, L.C. and Schindler, R.M. (2003). Cultural superstitions and the price endings used in Chinese advertising, Journal of International Marketing, 11, 101-111.

[14] Singh, M. (2002). Stress Scale [Measurement Instrument]. Mumbai, Maharashtra: Institute of Research and Test Development

[15] Skinner, B.F.(1953). Science and human behaviour. New York.NY: Macmillan.

[16] Vyse,S.A. (1997). Believing in Magic The Psychology of superstition. New York.NY. Oxford University Press.

[17] Wright, P.B., Erdal, K.J. (2008). Sport superstition as a function of skill level and task difficulty. Journal of sport behavior. 31(2). P.187-199. Retrieved from: http://connection.ebscohost.com/c/articles/31951659/sport-superstition-as-function-skill-leveltask-difficulty

\footnotetext{
*Corresponding author.

E-mail address: manasvi.shri@ gmail.com
} 